\title{
Analytical And Experimental Study Of Three Test-Run Balancing Method
}

\author{
Sabah. M. Jamil Ali \\ Mohammed T. S. Al-Taee \\ prosabah7447@yahoo.com \\ zahars2004@yahoo.com
}

Gaydaa I. H. AL-Sarraj

\author{
engmohammed77@hotmail.com
}

\begin{abstract}
:
In this research, a single-plane balancing method based only on vibration amplitude readings has been adopted. This method has been thoroughly discussed including the analytical basis as well as the practical procedure. Balancing according to this methodusually performed by adobting the diagram procedure (Drawing). However; this researchunprecedently-establishes a mathematical analysis base for this method which makes it easy programmed, saving time and effort as well as attaining high-accuracy findings. As to the current work; an experimental test rig prepared by AL-Taee [9] has been used to obtain the required vibration measurement where they have been fed as input data into a $(C)$ language computer program that successfully accounts the magnitude and location of the weight required to balance the test rig rotor, as well as allowing disk's safe rotating process during its running speed.
\end{abstract}

Key words: Three Test-Run Balancing Method and Single Plane Balancing.

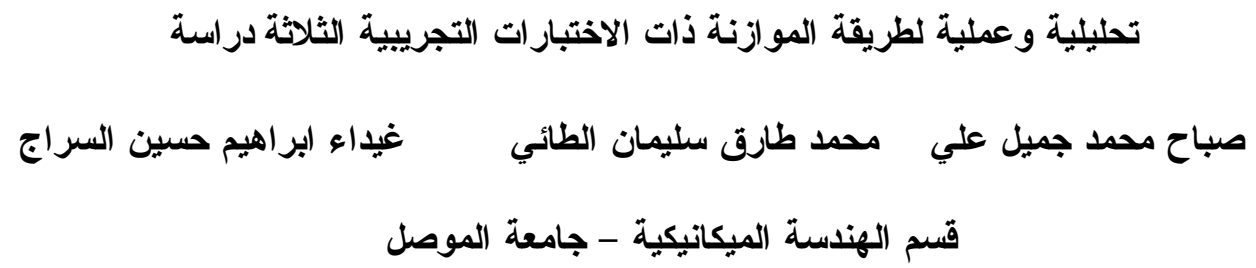

الخلاصة

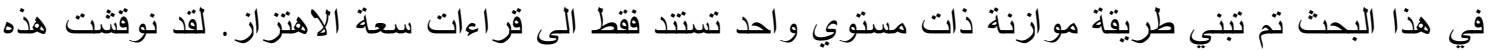

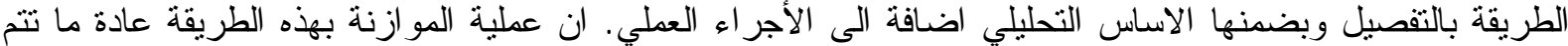

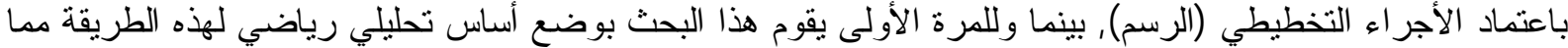

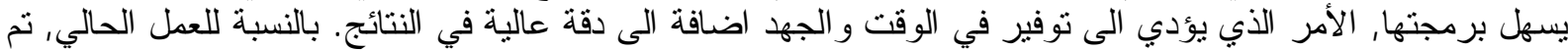

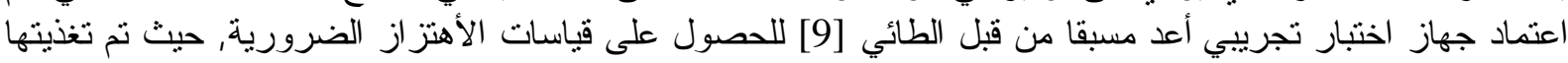

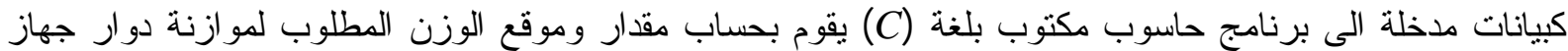

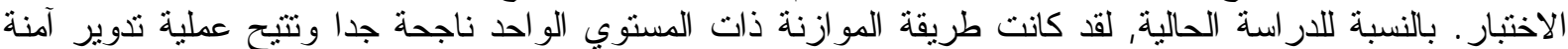
اللقرص الدوار خلال سرعته التشغيلية. الكلمات الاليلية: طريقة المو ازنة ذات الأختبار ات التجريبية الثلاثة و اسلوب مو ازنة ذات مستوي واحد. 


\section{Notations}

$V \quad$ Vibrational amplitude at the measuring point due to original unbalance of rotor.

$V_{t} \quad$ Vibrational amplitude at the measuring point due to a trial mass mounted at any angle on the balancing plane.

$V_{o} \quad$ Vibrational amplitude at the measuring point due to the original unbalance plus a trial mass mounted at $\left(0^{\circ}\right)$ angle on the balancing plane.

$V_{120}$ Vibrational amplitude at the measuring point due to the original unbalance plus a trial mass mounted at $\left(120^{\circ}\right)$ angle on the balancing plane.

$V_{240}$ Vibrational amplitude at the measuring point due to the original unbalance plus a trial mass mounted at $\left(240^{\circ}\right)$ angle on the balancing plane.

$\varphi \quad$ Phase angle due to original unbalance of rotor.

$M \quad$ Magnitude of balancing mass.

$M_{\text {trial }}$ Trial mass.

\section{Introduction:}

Although vibration may be caused by a variety of conditions such as bent shafts, misaligned couplings or bearings, foundation failure, etc., unbalance is the most common source of high vibration that affect rotating equipments [1]. Consequently, precision balancing for rotating equipments is essential for machine performance. Sources of unbalance in rotating machinery may be classified as resulting from dissymmetry, nonhomogeneous material, distortion at service speed (blower blades in built-up designs), shifting of parts due to plastic deformation of rotor parts(windings in electric armatures), etc., [2]. In some practical problems it may be necessary to attempt field balancing without the use of phase measuring equipment. This may be due to the rotating parts of the machine to be balanced being completely enclosed, or simply due to no phase measuring equipment being available. In these cases it is possible to achieve a good degree of balance using amplitude measuring equipment (i.e., vibration meter). According to Foiles et al [3], Karelitz, Ribary, Hopkirk and Somervaille [4] were the early researchers who using the amplitude measuring method. Somervaille's construction is known as the four - circle method of balancing without phase. The four circle method, as it is generally used now [3], can be found in Jackson [5]. Wilcox [6] presented a graphical construction for single plane that balanced using only the amplitude taken from an initial run and four trial mass runs. Nisbett [7] performed a simple practical procedure of two - plane balancing using only amplitude measuring equipment. Nisbett found that most simple rotors can be balanced by applying this technique iteratively; this technique took eight trial mass runs, and it can be used in the field effectively. Mah et al [8] checked experimentally the graphical amplitude measuring method for single plane balancing on a narrow rotor. Their technique took four runs, an initial and three trial mass runs. They showed that vibration of the test narrow rotor was decreased at the bearing with a humble improvement of (29\%).

AL-Taee [9] performed a simple analytical and practical method for a single - plane balancing using only amplitude measuring equipment. He conducted a computer program to evaluate the validity of his balancing procedure on a test rig rotor. His technique tooks four trial mass runs, and it can be used in the field effectively.

The work in this paper aims to solve the problem of mass unbalance that affect discshaped rotors such as centrifugal pumps, fans, motors, grinding and turbine wheels, etc., achieve balancing on a test rig using vibration amplitude readings taken from an initial run 
and three trial mass runs. A novel theoretical analysis to develop mathematical equations and implement it in a computer program specifically written by the authors. A simple flow chart of the written computer program can be seen in Appendix $(A)$.

\section{Theoretical Analysis:}

In this paper, the basic assumption is that vibration is due to pure unbalance and that most vibration occurs at the machine running speed. Vibration measurements must be taken as close as possible to one of the machine's support bearings. However, once a location for taking the vibration measurements has been decided on, it is important that all vibration measurements are taken at exactly the same location and direction. Three test-runs of trial mass are required, with the trial weight placed individualy on the rotor at $\left(0^{\circ}\right),\left(120^{\circ}\right)$ and $\left(240^{\circ}\right)$, where zero degree is an arbitrary position chosen by the user. By using these measurements to draw a vector digram, it is now possiple to calculate the residual unbalance in the rotor. Such a vector digram is depicted in figure (1). Two important variables must be known in order to achieve balancing, the amount of the balancing weight and its location on the rotor.

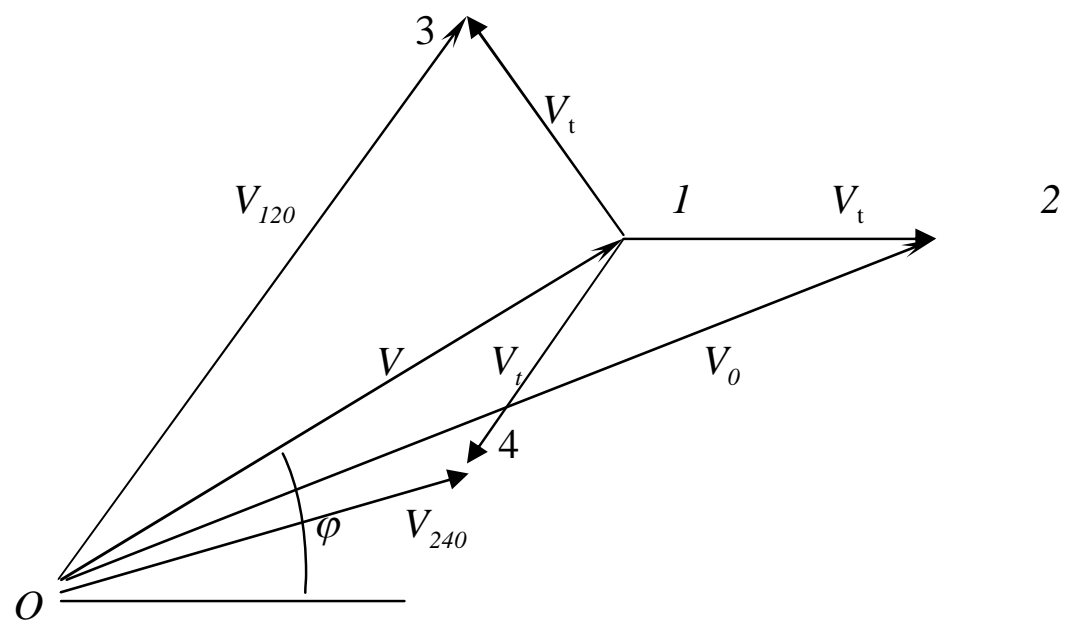

Figure (1). Vector diagram

From figure (1), triangle (O12), and using the cosine law, we obtain;

$$
V_{0}^{2}=V^{2}+V_{t}^{2}-2 V V_{t} \cos (180-\varphi)
$$

or

$$
V_{0}^{2}=V^{2}+V_{t}^{2}+2 V V_{t} \cos \varphi
$$

Similarly, from figure (1), triangle (O13) , and using the cosine law, we obtain;

where $\cos (60+\varphi)=(\cos 60 \cos \varphi-\sin 60 \sin \varphi)$

or

$$
V_{120}^{2}=V^{2}+V_{t}^{2}-2 V V_{t}(\cos 60 \cos \varphi-\sin 60 \sin \varphi)
$$

In the same way, from figure (1), triangle (O14), the following equation can be obtained, 


$$
V_{240}^{2}=V^{2}+V_{t}^{2}-2 V V_{t} \cos (60-\varphi)
$$

or

$$
V_{240}^{2}=V^{2}+V_{t}^{2}-2 V V_{t}(\cos 60 \cos \varphi+\sin 60 \sin \varphi)
$$

where $\cos (60-\varphi)=(\cos 60 \cos \varphi+\sin 60 \sin \varphi)$

By adding equation (1), (2) and (3), gets,

$$
V_{0}^{2}+V_{120}^{2}+V_{240}^{2}=3 V^{2}+3 V_{t}^{2}
$$

or

$$
V_{t}=\sqrt{\frac{\left(V_{0}^{2}+V_{120}^{2}+V_{240}^{2}-3 V^{2}\right)}{3}}
$$

By subtracting equation (2) from (3) results,

$$
V_{240}^{2}-V_{120}^{2}=-4 V V_{t} \sin 60 \sin \varphi
$$

or

$$
\sin \varphi=\frac{V_{120}^{2}-V_{240}^{2}}{4 V V_{t} \sin 60}
$$

By re-arranging equation (1),

$$
\cos \varphi=\frac{V_{0}^{2}-V^{2}-V_{t}^{2}}{2 V V_{t}}
$$

By dividing equation (10) by (11), gets,

$$
\tan \varphi=\frac{V_{120}^{2}-V_{240}^{2}}{V_{0}^{2}-V^{2}-V_{t}^{2}}
$$

thus

$$
\varphi=\tan ^{-1}\left[\frac{V_{120}^{2}-V_{240}^{2}}{2\left(V_{0}^{2}-V^{2}-V_{t}^{2}\right) \sin 60}\right]
$$

The purpose of calculating these $(\varphi)$ and $\left(V_{t}\right)$ values is ultimately to determine the mass and its location on the rotor that will eliminate the vibration at the bearing. equation,

Let this correction mass be identified as $(M)$, which can be found from the following

$$
M=\frac{V}{V_{t}} M_{\text {trial }}
$$




\section{Ali: Analytical And Experimental Study Of Three Test-Run Balancing Method}

\section{Experimental Work:}

An actual arrangement of the adopted experimental test rig is shown in figure (2). This rig has been prepared by AL-Taee [9], where a complete explanation has been presented. The rig consists of a thin plastic disc, and a clockwise A.C. motor. In this work, the motor speed of $(1425 \mathrm{rpm})$ represents the running speed of the disc. Steps of the experimental balancing procedure of the disc are described in details in Appendix $(B)$.

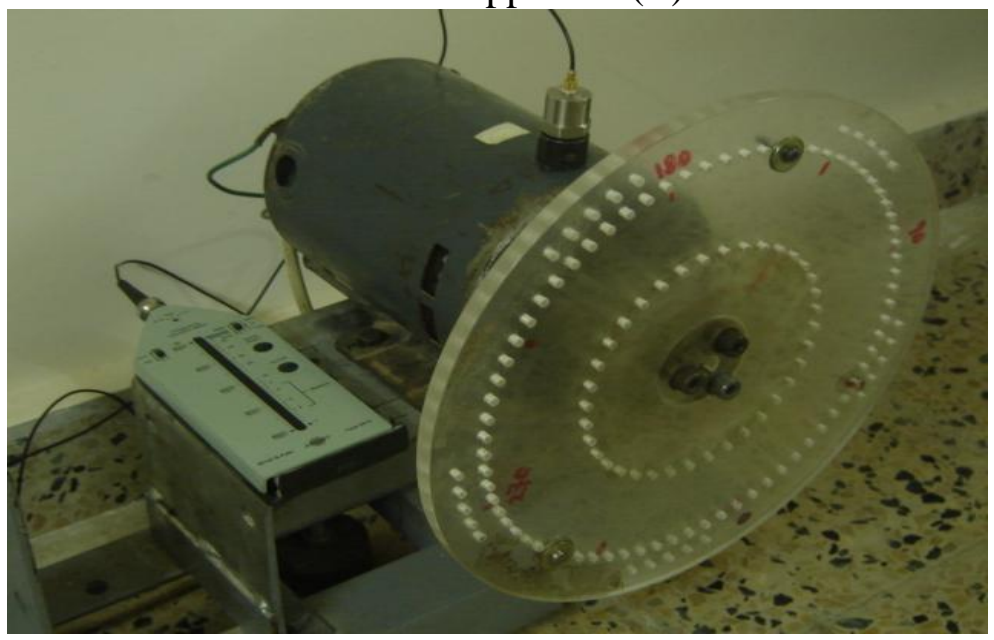

Figure (2). Experimental test rig

\section{Results and Discussion:}

Table (1) shown below, gives the measured vibration levels in the measuring plane for the test speed corresponding to an original unbalance condition of the rotor, trial mass is placed in the balancing plane at $\left(0^{\circ}\right),\left(120^{\circ}\right)$ and $\left(240^{\circ}\right)$ respectively.

\begin{tabular}{||c||c|c||c|c|}
\hline $\begin{array}{c}\text { Rotor speed } \\
(\mathrm{rpm})\end{array}$ & $\begin{array}{c}\text { Test } \\
\text { number }\end{array}$ & $\begin{array}{c}\text { Test } \\
\text { number }\end{array}$ & $\begin{array}{c}\text { Trial mass size and location } \\
\left(M_{\text {trial }}=4.72 \text { gram }\right)\end{array}$ & $\begin{array}{c}\text { Vibrational } \\
\text { velocity } \\
(\mathrm{mm} / \mathrm{sec})\end{array}$ \\
\hline \hline \multirow{3}{*}{1425} & 1 & $V$ & Original unbalance & 2.42 \\
\cline { 2 - 6 } & 2 & $V_{0}$ & $M_{\text {trial }}$ in balancing plane at $\left(0^{\circ}\right)$ & 0.92 \\
\cline { 2 - 6 } & 3 & $V_{120}$ & $M_{\text {trial }}$ in balancing plane at $\left(120^{\circ}\right)$ & 3.70 \\
\hline
\end{tabular}

Table (1). Measured vibration levels of the disc

The measured amplitude velocity values of tests (1 to 4) recorded in table (1), have been supplied as input data to the single - plane balancing program, which is based on the amplitude velocity readings (i.e., no phase readings). The calculated balancing mass $(M)$ was installed at its phase angle from the reference point at $\left(0^{\circ}\right)$. Then the disc was brought up to the running speed of $(1425 \mathrm{rpm})$ and the resulting vibrational velocity was observed at the measuring point on the motor case. 
In the other side, a graphical solution has been sighted in [8], where it has been implemented experimentally on a specific disc. The authors decided to use it as part of their present work and as a double check to the results obtained using the computer program based on the analytical solution. The vector method of balancing is the classical approach to this subject. It is very reliable and gives the user an appreciation of how the balancing process works. To apply this procedure, an assumption that the amplitude of the vibration is proportional to the amount of unbalance. The magnitude of the amplitude velocity represents the vector length of vibration. By selecting an appropriate scale, a circle with radius proportional to the original unbalance $(V)$ can be constructed. The trial mass of (4.72 gram) is applied at three angular positions $0^{\circ}, 120^{\circ}$ and $240^{\circ}$ at a time. The origins of the circles for each positions are drawn along the circumference of the original vibration circle, with respect to its corresponding angle. After the three circles are drawn, a common intersection point is found, point $(P)$. By drawing a line from the origin $(O)$, of the impedance circle to point $(P)$, a length $\left(V_{t}\right)$ can be measured. By applying the previously set scale, the magnitude of the correction mass can be calculated from equation (14).

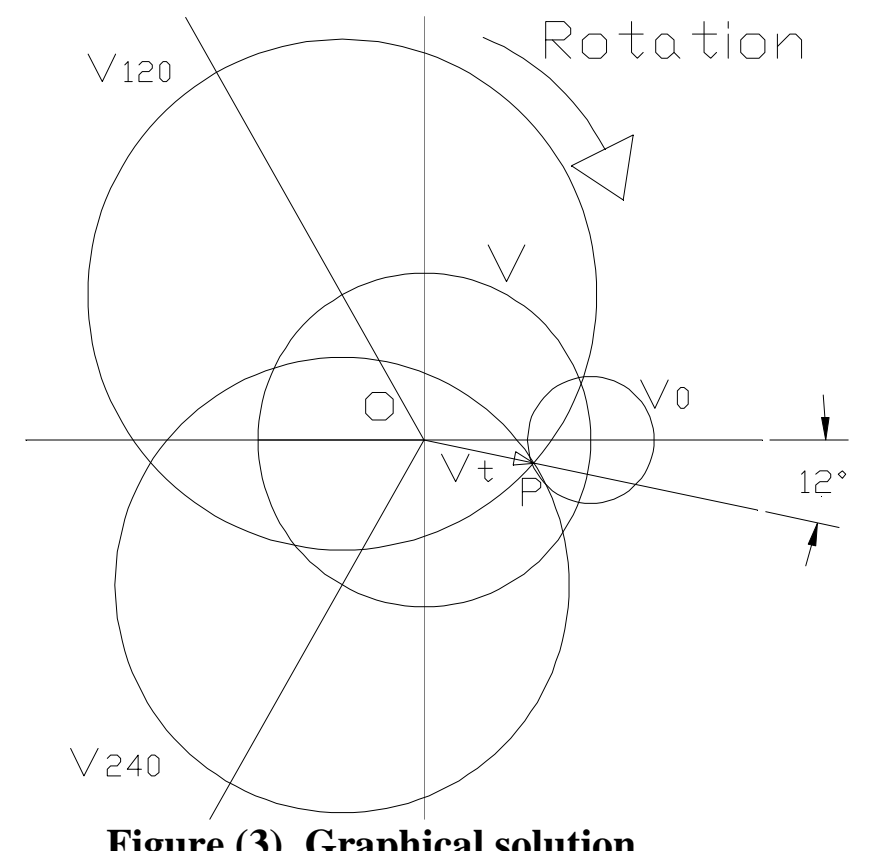

Figure (3). Graphical solution

Table (2) shown below, gives the required balancing mass and its phase angle for both analytical and graphigal procedure.

\begin{tabular}{||c|c|c|}
\hline \multicolumn{1}{|c||}{ Balancing procedure } & $\begin{array}{c}\text { Analytical } \\
\text { (Computer program) }\end{array}$ & Graphical \\
\hline $\begin{array}{l}\text { Magnitude of balancing } \\
\text { mass (gram) }\end{array}$ & 7.058040 & 7.058039 \\
\hline $\begin{array}{l}\text { Phase angle in the } \\
\text { ccw direction (degree) }\end{array}$ & 348.036 & 348.000 \\
\hline
\end{tabular}

Table (2). Calculated results of the rotor disc using analytical and graphical procedure 
Table (3) shown below, gives a comparison of vibration level of the disc before and after balancing.

\begin{tabular}{|c|c|c|c|}
\hline \multirow{3}{*}{$\begin{array}{l}\text { Rotor speed } \\
\quad(\mathrm{rpm})\end{array}$} & \multicolumn{3}{|c|}{ Motor case } \\
\hline & \multicolumn{2}{|c|}{ Vibrational acc. $\left(\mathrm{mm} / \mathrm{s}^{2}\right)$} & \multirow{2}{*}{$\begin{array}{l}\text { Percentage improvement } \\
\qquad(\%)\end{array}$} \\
\hline & $\begin{array}{c}\text { Before } \\
\text { balancing }\end{array}$ & $\begin{array}{c}\text { After } \\
\text { balancing }\end{array}$ & \\
\hline 1425 & 2.42 & 0.227 & 90.62 \\
\hline
\end{tabular}

Table (3). Comparison of vibration level of the disc before and after balancing process

In commenting on table (3), the $\left(2.42 \mathrm{~m} / \mathrm{s}^{2}\right)$ original unbalance value is reduced after balancing to the $\left(0.227 \mathrm{~m} / \mathrm{s}^{2}\right)$ residual unbalance value which gives a good improvement in the form of reduction in the value of vibration at the test speed.

\section{Conclusions:}

The experimental test program used here has shown that a disc shaped rotor can be systematically balanced at its running speed. The single plane balancing method based on amplitude mesurements is found very effective, practical, successful and permitting safe rotor operation through its running speed. From just a single balancing run, an acceptable improvement of $(90.62 \%)$ has been obtained as well as an excellent agreement between the analytical solution (i.e., computer program) and the graphical solution has been achieved.

\section{References:}

1. AL-Taee, M. T., " Dynamic Balancing of Rotating Shafts by Vibration Measurements" M.Sc Thesis, Department of Mechanical Engineering, University of Baghdad, November (2004).

2. arris, C. M. and Piersol, A. G., "Harris' Shock and Vibration Handbook" McGraw-Hill Professional, New York, Fifth edition, (2002).

3. Foiles, W. C., Allaire, P. E. and Gunter. E. J., " Review: Rotor Balancing " Shock and Vibration, vol. 5, (1998), pp. 325-336.

4. Karelitz, Ribary, Hopkirk and Somervaille Somervaille, I. J., "Balancing a Rotating Disc, Simple Graphical Construction ”, Engineering (1954), pp. 241-242.

5. Jackson, C., " The Practical Vibration Primer ", Gulf Publication, Houston, Texas, (1979).

6. Wilcox, J. B., “ Dynamic balancing of rotating machinery ", Nottingham Regional College of Technology, Sir Isaac Pitman and Sons Ltd., London, First published (1967).

7. Nisbett, k., " Dynamic Balancing of Rotating Machinery Experiment ", January (1996), http://web.umr.edu/ stutts/ME242/LABMANUAL/DynamicBalancing Exp.pdf.

8. Mah, C., Hesp, B., Boden, C. and Thannhauser, S., " Laboratory V2: Dynamic Balancing ", Department of Mechanical Engineering, University of Saskatchewan, October (2002).

9. AL-Taee, M. S., “ THEORETICAL AND EXPERIMENTAL METHOD OF ROTATING DISCS BALANCING ", AL-Rafidain Engineering Journal, Mosul University, vol. 5, (2008), to be published. 
10. Norfield, D., “ Practical Balancing of Rotating Machinery ”, Elsevier Ltd. Publication, Oxford, UK., First edition, (2006).

\section{$\underline{\text { Appendix }(A)}$}

Flow Chart of the Written Computer Program

In this appendix, figure $(A)$ shown below represents a flow chart of the computer program written based on the adopted single-plane balancing method.

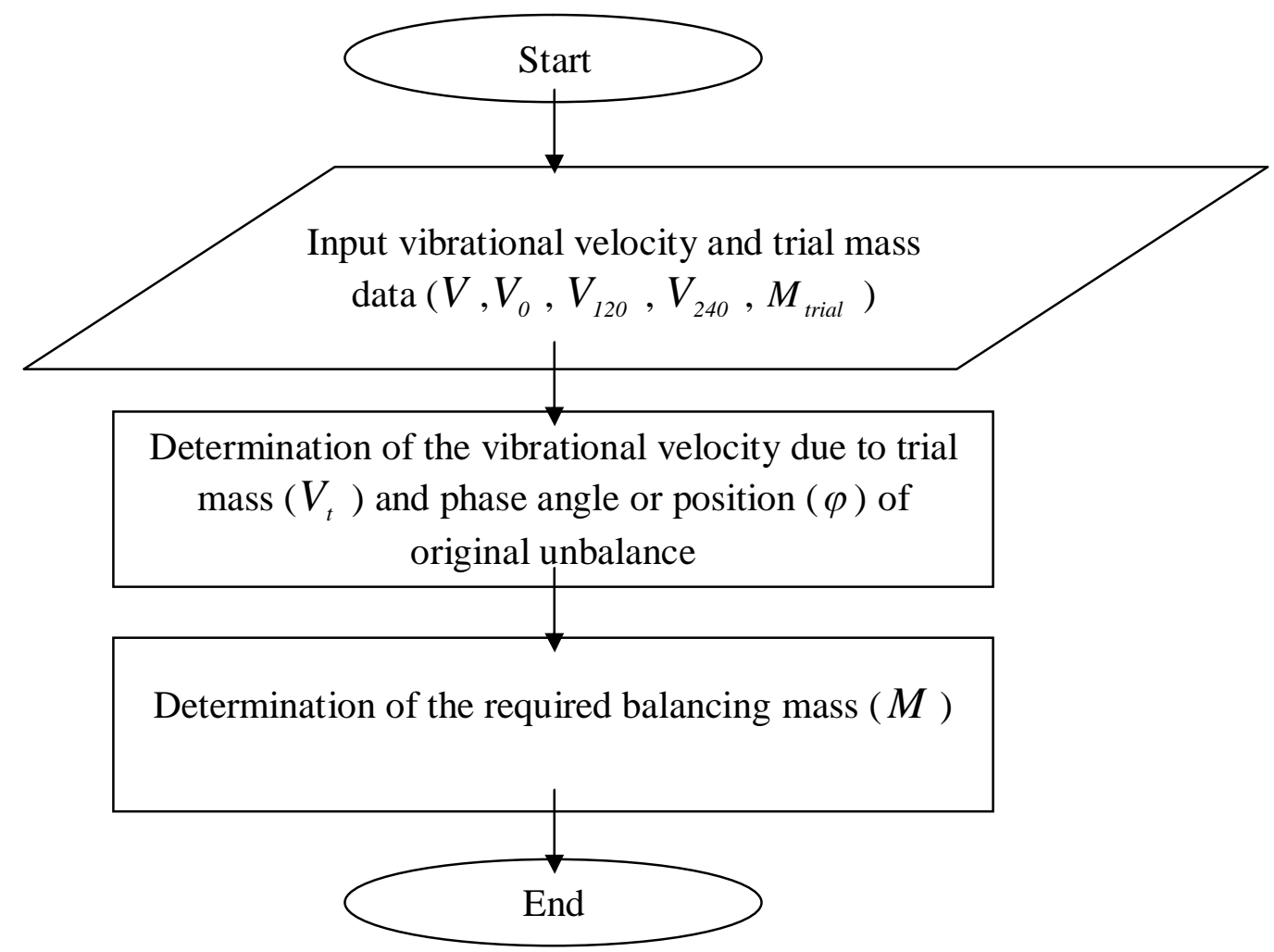

Figure (A). Flow Chart of Computer Program Based on the

Single - Plane Balancing Method

\section{$\underline{\operatorname{Appendix}(B)}$}

In this appendix, steps of the experimental balancing procedure of the disc are described in detail as shown below.

a. The accelerometer was attached to the motor case in the vertical direction by means of a magnetic base (screwed to the accelerometer) as shown in figure (2).

b. The rotor was allowed to run to the test speed (i.e., $1425 \mathrm{rpm}$ ) for about two minutes to reach the steady state condition.

c. With only the new original unbalance condition, vibrational velocity $(V)$ was measured at the test speed. 
d. The rotor was stopped, and the trial mass of ( 4.72 gram) was attached to the $\left(0^{\circ}\right)$ position on the rotor. Zero degree is an arbitrary position chosen by the user. (The trial mass should be firmly attached to the rotor. It is a serious safety risk if the trial mass is not firmly attached and flies off while running the rotor).

For actual rotating part, the trial mass (i.e., initial balancing mass) value can be calculated using one of the well-known formulas (ISO1940, API 610 or ANSI), the following formula is defined by ISO1940 [10],

$$
\text { Balance Tolerance }(\text { gram }-\mathrm{mm})=\frac{9.54 * \text { G number } * \text { Rotor mass }(\text { gram })}{R P M}
$$

or

$$
\text { Trial mass value }(\text { gram })=\frac{9.54 * G \text { number } * \text { Rotormass }(\text { gram })}{R P M * r(m m)}
$$

where $(G)$ is the balance quality grade of the rotor and $(r)$ is the radius where the trial mass is fixed on the rotor.

e. The rotor was restarted and brought up to the test speed. Vibrational velocity $\left(V_{0}\right)$ was measured with the trial mass at $\left(0^{\circ}\right)$.

f. The rotor was stopped and the trial mass was removed from the $\left(0^{\circ}\right)$ position and reattached at the $\left(120^{\circ}\right)$ position.

g. The rotor was restarted and brought up to the test speed. Vibrational velocity $\left(V_{120}\right)$ was measured with the trial mass at $\left(120^{\circ}\right)$.

h. The rotor was stopped and the trial mass was removed from the $\left(120^{\circ}\right)$ position and reattached at the $\left(240^{\circ}\right)$ position.

i. The rotor was restarted and brought up to the test speed. Vibrational velocity $\left(V_{240}\right)$ was measured now with the trial mass at $\left(240^{\circ}\right)$.

j. The rotor was stopped and the trial mass was removed from the $\left(240^{\circ}\right)$ position.

k. The calculated balancing mass $(M)$ is attached at its calculated balancing angle, then rotor restarted until brought up to its running speed. 